\title{
Cardiopulmonary Bypass Management Using High-volume Continuous Hemofiltration in Patients with Comorbidities
}

(1) Georgiy Plotnikov, (1) Vadim Popov, (1) Vladimir Chagirev, (ㄱ Giorgiy Edzhibiya, (1) Egor Malyshenko, (1) Amiran Revishvili

A.V. Vishnevsky National Medical Research Center of Surgery, Clinic of Cardiovascular Diseases, Moscow, Russian Federation

\begin{abstract}
Objectives: To evaluate the effectiveness of hemofiltration during longstanding cardiopulmonary bypass (CPB) in patients with comorbidities.

Materials and Methods: Prospective randomized clinical trial included 38 male patients with ex-pecting duration of $\mathrm{CPB}>120$ minutes due to comorbid pathology. Standard anesthesia protocol was carried out. Study includes two groups: first group (controlled, $\mathrm{n}=20$ ) included standard $\mathrm{CPB}, 2^{\text {nd }}$ group (analyzed, $\mathrm{n}=18$ ) included perfusion with high-volume hemofiltration using polyionic buffered solution $80 \mathrm{~mL} / \mathrm{min}$ during all CPB time. Hemofiltration has been also supported by ultra-filtration for hydro-balance maintenance at the level of $8-10 \mathrm{~mL} / \mathrm{kg}$. Laboratory tests, respiratory and renal complications, drainage blood loss,
\end{abstract}

hemostasis disorders, requiring hemostatics and blood transfusion, intensive care unit (ICU) and in-hospital were evaluated. Nonparametric methods-Mann-Whitney U test for independent samples and Wilcoxon signed-rank test for dependent samples were used.

Results: IL-6 level in 2nd group was significantly lower ( $\mathrm{p}=0.0017)$ and did not exceed $7.4 \mathrm{pg} / \mathrm{mL}$. C-RP, metalloproteinase and procalcitonin levels were lower too, but not statistically significant. Lactate level in analyzed group was in reference range, while in control group after perfusion it in-creased to $8.3 \pm 4.2 \mathrm{mmol} / \mathrm{L}$. Renal dysfunction, requiring dialysis, was diagnosed in six $(20,7 \%)$ patients from controlled group vs two patients (6.1\%) from analyzed group. Respiratory insufficiency

\footnotetext{
Address for Correspondence: Vladimir Chagirev, A.V. Vishnevsky National Medical Research Center of Surgery, Clinic of Cardiovascular Diseases, Moscow, Russian Federation

Phone: +7 9645340315 e-mail: chagirevmed@gmail.com ORCID ID: orcid.org/0000-0002-2810-9142

Received: 15.02.2019 Accepted: 22.05.2019
}

Cite this article as: Plotnikov G, Popov V, Chagirev V, Edzhibiya G, Malyshenko E, Revishvili A. Cardiopulmonary Bypass

Management Using High-volume Continuous Hemofiltration in Patients with Comorbidities. EJCM 2019;7(2):79-83.

DOI: $10.32596 /$ ejcm.galenos.2019.00019

${ }^{\circ}$ Copyright 2019 by Heart and Health Foundation of Turkey (TÜSAV) / E Journal of Cardiovascular Medicine published by Galenos Publishing House. 
developed in three patients $(10.3 \%)$ only in controlled group. In-hospital stay was significantly lower in analyzed group and so was the ICU length. Polyorganic insufficiency syndrome occurred in three patients (10.3\%) from the controlled group.

Conclusion: High-volume hemofiltration using polyionic

\section{Introduction}

Despite the development of new technologies and cardiopulmonary bypass (CPB) techniques, its negative effects still remain significant ${ }^{(1)}$. Systemic inflammatory response makes serious contribution to the pathophysiology and it depends on surgical trauma, blood and artificial surfaces interactions during extracorporeal circulation, ischemia/reperfusion, endotoxemia and etc ${ }^{(2)}$. At the same time, number of patients with organic dysfunction due to comorbidities is increasing every year. That is why preventing of inflammatory response during $\mathrm{CPB}$ can lower postoperative complications. For example, invention of centrifugal pumps influenced a lot CPB management in cardiac surgery. Recent studies are showing advantages of using centrifugal pumps over roller pumps ${ }^{(3)}$. But the conclusions are still controversial, since these studies included only operations with perfusion duration less than 90 minutes. The magnitude of complement activation is proportional to the duration of $\mathrm{CPB}^{(4)}$. There are several ways to reduce the inflammatory response, such as ultrafiltration, plasmafiltration, hemosorption (with polymethyl methacrylate). All of them have proven their effectiveness, but still there is a lack of data in using these methods. Also Rabie Soliman et al. in his research discovered that hemofiltration can cause lactate level in serum $^{(5)}$. Currently, there are no guidelines to the CPB management during surgeries with different perfusion time. Correlation between mediators of inflammatory response level during and after $\mathrm{CPB}$ and the incidence of organic insufficiency is not evaluated in any studies. buffered solution for longstanding $\mathrm{CPB}$ reduces damaging effects of traditional roller pump and reduces risks of organic dysfunction in postoperative period.

Keywords: Cardiopulmonary bypass, hemofiltration, systemic inflammatory response

\section{Materials and Methods}

Prospective randomized clinical trial with 38 male patients included with CPB duration over 120 minutes during concomitant heart surgery. Inclusion criteria: patients with coronary artery disease and/or heart valve disease with the history of atrial fibrillation and comorbidities (chronic pyelonephritis, chronic obstructive pulmonary disease, diabetes mellitus), requiring coronary artery bypass grafting (CABG) surgery and/or valve surgery and "maze" procedure. Patients who underwent urgent surgery were excluded from the trial. The study was approved by the local ethic committee; informed consent was signed by all patients. Standard anesthesia protocol was carried out. Study includes two groups: First group (controlled, $\mathrm{n}=20$ ) included standard $\mathrm{CPB}, 2^{\text {nd }}$ group (analyzed, $\mathrm{n}=18$ ) included perfusion with high-volume hemofiltration using polyionic buffered solution $80 \mathrm{~mL} /$ min during all CPB time. Hemofiltration has been also supported by ultrafiltration for hydro-balance maintenance at the level of $8-10 \mathrm{~mL} / \mathrm{kg}$. For the study we are using Maquet hemoconcentrators with priming volume $65 \mathrm{~mL}$ and membrane surface $0.7 \mathrm{~m}^{2}$ and as a substitute solution MultiBic bicarbonate buffer solution with potassium concentration $4 \mathrm{mmol} / \mathrm{L}$ was used. Hemofiltration ends after weaning from CPB.

\section{Statistical Analysis}

Main clinical data, such as age, weight, CPB duration and others were comparable in both groups (Table 1). Envelope randomization was carried out. Laboratory tests (WBC, Hb, Plt, IL-6, IL-10, lactate, procalcitonin, 
C-RP) were evaluated, as well as respiratory and renal complications, drainage blood loss, hemostasis disorders, requiring hemostatics and blood transfusion, ICU and inhospital.

All operations included in this study in both groups were concomitant, such as coronary artery bypass surgery with the valve repair or replacement and atrial fibrillation surgery, and all of them required long CPB and cross-clamping time (Table 2). Data in both groups was comparable. All results presented as mean value \pm standard deviation $(\sigma)$. To evaluate the diversity significance between all parameters Student's t-test was used. P-level $<0.05$ was considered as significant.

\section{Results}

IL-6 level was significantly lower in analyzed group $(\mathrm{p}=0.0017)$ and did not exceed 7.4 picogram per $\mathrm{mL}$, while

Table 1. Clinical data

\begin{tabular}{|c|c|c|}
\hline & $\begin{array}{l}\text { Control } \\
\text { group } \\
(n=20)\end{array}$ & $\begin{array}{l}\text { HVH } \\
\text { group } \\
(n=18)\end{array}$ \\
\hline Age, years & $69.3 \pm 11.3$ & $72.1 \pm 12.7$ \\
\hline Weight, kg & $74.9 \pm 9.4$ & $71.9 \pm 12.6$ \\
\hline HF (NYHA class), n (\%): & $20(100)$ & $18(100)$ \\
\hline II & $11(55)$ & $10(55.6)$ \\
\hline III & $9(45)$ & $8(44.4)$ \\
\hline \multicolumn{3}{|l|}{ Comorbidities: } \\
\hline Renal failure (RIFLE), n (\%) & $6(30)$ & $5(27.8)$ \\
\hline $\mathrm{R}$ & $2(10)$ & $2(11.1)$ \\
\hline I & $3(15)$ & $2(11.1)$ \\
\hline $\mathrm{F}$ & $1(5)$ & $1(5.55)$ \\
\hline $\begin{array}{l}\text { Respiratory failure, } n \text { (\%) (A.G.Dembo } \\
\text { chronic respiratory insufficiency } \\
\left.\text { classification }{ }^{(6)}\right)\end{array}$ & $8(40)$ & 7 (38.9) \\
\hline 1 & $2(10)$ & $1(5.6)$ \\
\hline II & $4(20)$ & $4(22.2)$ \\
\hline III & $2(10)$ & $2(11.1)$ \\
\hline Diabetes mellitus, $\mathrm{n}(\%)^{*}$ & $8(40)$ & $7(38.9)$ \\
\hline EuroSCORE 2, \% & 4.3 & 3.7 \\
\hline
\end{tabular}

IL-10 level was comparable in both groups (Table 3). Also procalcitonin, C-RP levels were lower, but not statistically relevant. Lactate level remained normal, while in control group it has been increased to $8.3 \pm 4.2 \mathrm{mmol} / \mathrm{L}$ after perfusion. Transfusion rate were the same in both groups, but patients from analyzed group didn't require any hemostatic therapy. There was no need in inotropic and vasopressor medications in the analyzed group by the end of the first postoperative day, all patients were extubated in first postoperative hours. Renal dysfunction, requiring dialysis, was diagnosed in $6(20.7 \%)$ patients from controlled group vs. two patients $(6.1 \%)$ from analyzed group. Respiratory insufficiency developed in three patients $(10.3 \%)$ only in controlled group. In-hospital stay was significantly lower in analyzed group and so was the ICU length. Polyorganic insufficiency syndrome occurred in three patients $(10.3 \%)$ from the controlled group.

\section{Discussion}

The use of CPB in major cardiac surgery initiates an acute inflammatory response that is complex, unpredictable and can cause significant morbidity and mortality, especially during long-standing procedures. Pathophysiology of CPB negative effects can be summarized as generalized inflammatory response,

Table 2. Operative data

\begin{tabular}{|l|l|l|}
\hline & $\begin{array}{l}\text { Control } \\
\text { group } \\
(\mathbf{n = 2 0})\end{array}$ & $\begin{array}{l}\text { HVH } \\
\text { group } \\
(\mathbf{n = 1 8})\end{array}$ \\
\hline CABG + MV replacement + RFA, n (\%) & $6(30)$ & $5(27.8)$ \\
\hline CABG + MV repair + RFA n (\%) & $7(35)$ & $9(50)$ \\
\hline $\begin{array}{l}\text { CABG + MV replacement + LV aneurysm } \\
\text { repair + RFA n (\%) }\end{array}$ & $1(5)$ & $1(5.5)$ \\
\hline AV and MV replacement + RFA n (\%) & $4(20)$ & $1(5.5)$ \\
\hline AV replacement + CABG + RFA n (\%) & $2(10)$ & $2(11.1)$ \\
\hline CPB duration, min & $182 \pm 44$ & $176 \pm 52$ \\
\hline Cross-clamp time, min & $145 \pm 27$ & $142 \pm 39$ \\
\hline Surgery duration, min & $330 \pm 56$ & $340 \pm 60$ \\
\hline Intraoperative blood loss, mL & $725 \pm 55$ & $730 \pm 65$ \\
\hline
\end{tabular}

HVH: High-volume hospital, CABG: Coronary artery bypass grafting, MV: Mitral Valve, RFA: Radiofrequency ablation, LV: Left ventricular, AV: Atrioventricular, CPB: Cardiopulmonary bypass, $n$ : Number of the patients 
ischemia-reperfusion injury, endotoxemia, and operative trauma. Also the longer cardiopulmonary bypass was, the more expressed inflammatory response was $^{(7)}$. At the same time, number of patients with organic dysfunction is increasing every year, as well as CPB duration during complex concomitant surgery. That is why techniques to minimize the negative effects of inflammatory response during $\mathrm{CPB}$, allowing to reduce or remove alterative factors during perfusion, remain relevant ${ }^{(8)}$.

In our study main inflammatory response markers, that are always associated with long-standing CPB, were significantly lower, such as IL-6, IL-10 and others. Moreover, there were lower complication rate, less ICU and in-hospital stay, lower blood transfusion rate and there was no need in vasopressor and cardiotonic therapy in hemofiltration group. Most of the known approaches to reduce the $\mathrm{CPB}$ alterative effect are using minimally invasive extracorporeal circulation, improving of the circuit biocompatibility, using of centrifugal pumps ${ }^{(9-11)}$. But these techniques have their disadvantages too: absence of venous reservoir can increase the risk of air embolism. Also membranes in new oxygenators have better biocompatibility, but prevent blood saturation with isoflurane, so it is impossible to use inhalational anesthetics and their better protective effect on myocardium, which limits the use of this technology. High-volume continuous hemofiltration with standard roller pump CPB, that we offer, as we assume, doesn't have these disadvantages. Modified techniques of blood ultrafiltration ${ }^{(12,13)}$, hemosorption and apheresis ${ }^{(14,15)}$ removes small amount of liquid, that don't let us to accomplish clinical and laboratory evaluation of inflammatory mediators through the semipermeable membrane of hemofilter, leading to indifferent elimination of both inflammatory and antipyretic mediators. And the cost price of these procedures often exceed operations'

Table 3. Main laboratory data in early postoperative period

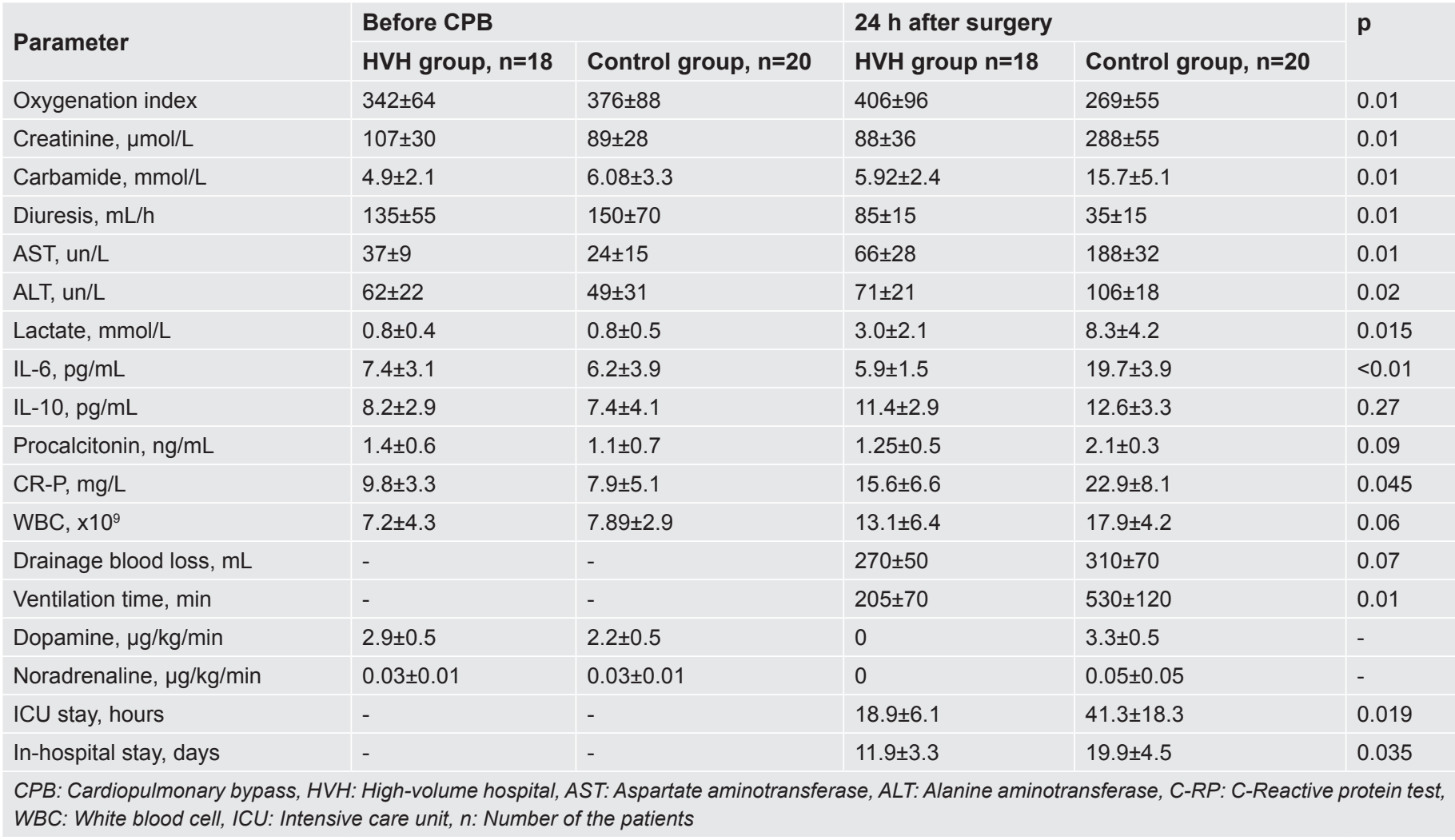


cost. Moreover, roller pump, used in these techniques initiates inflammatory response by itself and damages blood cells. In our study usage of polyionic buffer solution with hydro-balance maintenance at level 8-10 $\mathrm{mL} / \mathrm{kg}$ during long-standing CPB lowers these disadvantages. This study shows promising results in patients undergoing concomitant surgery with long cross-clamping time, but final results can be interpreted only after the full trial will be held.

\section{Ethics}

Ethics Committee Approval: This study was approved by A.V.Vishnevsky National Medical Research Center of Surgery local committee (approval no:23).

Informed Consent: All patients have signed informed consent.

Peer-review: Externally and internally peer-reviewed.

\section{Authorship Contributions}

Surgical and Medical Practices: V.P., A.R., E.M., Concept: G.P., Design: G.P., Data Collection or Processing: V.C., E.M., Analysis or Interpretation: V.P., G.P., A.R., E.M., Literature Search: V.C., G.E., Writing: G.E.

Conflict of Interest: No conflict of interest was declared by the authors.

Financial Disclosure: The authors declared that this study received no financial support.

\section{References}

1. Zakkar M, Guida G, Suleiman MS, Angelini GD. Cardiopulmonary bypass and oxidative stress. Oxid Med Cell Longev 2015;1-8. doi:10.1155/2015/189863

2. Heinzmann Bulow NM, Colpo E, Duarte MF, et al. Inflammatory response in patients under coronary artery bypass grafting surgery and clinical implications: a review of the relevance of dexmedetomidine use. ISRN Anesthesiology 2014. http://dx.doi.org/10.1155/2014/905238

3. Mlejnsky F, Klein AA, Lindner J, et al. A randomised controlled trial of roller versus centrifu-gal cardiopulmonary bypass pumps in patients undergoing pulmonary endarterectomy. Perfu-sion 2014;30:520-8. doi:10.1177/0267659114553283

4. Hirai S. Systemic inflammatory response syndrome after cardiac surgery under cardiopulmo-nary bypass. Ann Thorac Cardiovasc Surg 2003;9:365-70

5. Soliman R, Fouad E, Belghith M, Abdelmageed T. Conventional hemofiltration during cardio-pulmonary bypass increases the serum lactate level in adult cardiac surgery. Ann Card Anaesth 2016;19:45-51. doi: $10.4103 / 0971-9784.173019$

6. Kassil VL, Vyzhigina MA, Leskin GS. Artificial and assisted ventilation of the lungs. Mos-cow Medicine 2004. p. 408

7. Warren OJ, Smith AJ, Alexiou C, et al. The inflammatory response to cardiopulmonary by-pass: part 1- mechanisms of pathogenesis. J Cardiothorac Vasc Anesth 2009;23:223-31. doi:10.1053/j. jvca.2008.08.007

8. Di Tomasso N, Monaco F, Landoni G. Hepatic and renal effects of cardiopulmonary bypass. Best Pract Res Clin Anaesthesiol 2015;29:15161. doi:10.1016/j.bpa.2015.04.001

9. Pillai JB, Suri RM. Coronary Artery Surgery and Extracorporea Circulation: The Search for a New Standard. J Cardiothorac Vasc Anesth 2008;22:594-610. doi:10.1053/j.jvca.2008.02.004

10. Charnaya MA, Morozov Yu A, Gladysheva VG, Krapivkin IA. The influence of the technical characteristics of extracorporeal circuits on the platelet hemostasis, the system of fibrinolysis and the development of hemolysis. Vestn Ross Akad Med Nauk 2005;10:12-5.

11. Averina TB. Practical experience and substantiation of the use of biocompatible extracorporeal circuit coatings for the prevention of postperfusion complications in children. Children's dis-eases of the heart and blood vessels 2007;5:39-44

12. Tallman RD, Dumond M, Brown D. Inflammatory mediator removal by zero-balance ultrafil-tration during cardiopulmonary bypass. Perfusion 2002;17:111-5. doi:10.1191\%2F0267659102pf540oa

13. Averina TB. The importance of various methods of ultrafiltration in the optimization of perfu-sion support in children of the first year of life. Children's diseases of the heart and blood ves-sels 2007;5:32-8.

14. Khubulava GG, Marchenko SP, Dubova EV, Suvorov VV. The role of modified ultrafiltration in reducing systemic manifestations of inflammation in cardiac surgery. Pediatr 2016;7:106-10.

15. Solovyov IN, Belov Yu V. High volume plasmapheresis in cardiac and aortic surgery. Bulletin of anesthesiology and resuscitation 2018;15:2531. 